\title{
An Effective Solution to Single-Area Dynamic Dispatch Using Improved Chimp Optimizer
}

\author{
Ch. Leela Kumari ${ }^{1,2}$, Vikram Kumar Kamboj ${ }^{3 *}$ \\ ${ }^{1}$ Ph.D Research Scholar, School of Electronics and Electrical Engineering, Lovely Professional University, Punjab, India \\ ${ }^{2}$ Department of Electrical and Electronics Engineering, Bandari Srinivas Institute of Technology, Telangana, India \\ ${ }^{3}$ Domain of Power Systems, School of Electronics and Electrical Engineering, Lovely Professional University, Punjab, India \\ (Corresponding Author: Vikram Kumar Kamboj, vikram.23687@lpu.co.in)
}

\begin{abstract}
This paper proposes the Improved Chimp Algorithm (ICHIMP) to solve single area dynamic economic load dispatch (ELD) problem of electric power system. Chimp is a biologicallystimulated heuristic optimization technique, which is embedded on impersonating the technique chimps hunt for food and remain existent by escaping from their adversary. The particularity of ICHIMP is that the chimps move in group for hunting but each chimp searches the prey independently. The single area dynamic dispatch problem is described as non-linear, complex and forced optimization problem with objective function to curtail the total generation price, whereas fulfilling the correspondence and dissimilarity constraints of the system. This proposed algorithm has been tested on five different test systems consisting of 3,6,13,20 and 40- generating units.. The test results of ICHIMP determine its superiority over other existing algorithms addressed in literature and show that it outperforms for Single area dynamic dispatch problem of electric power system.
\end{abstract}

\section{INTRODUCTION}

Single area scalar objective economic dispatch Problem (ELDP) of electric power system is a key optimization issue in the power system network due to its complex, nonconvex, non-smooth and non-linear, characteristics [1]. In addition, economic dispatch is subjected to various kinds of correspondence and dissimilarity imperatives such as Balance power, transmission losses and ramp limits [2], [3]. According to [4], [5], To congregate the load demand at feasible price within the limits of transmission and operational capability of the system is achieved by Economic load dispatch, which is the best outcome of many electricity generation units.

The static economic dispatch as well as dynamic economic dispatch is categorized from economic dispatch as it is mentioned in [6],this static economic dispatch provides the optimum of the entire fuel price in a specified duration devoid of allowing for the fundamental relation of the systems between dissimilar operating periods whereas much attention is also required to pay when considering dynamic economic dispatch issue in connection of different operating times like as ramp rate limits, prohibited operating zones of generating units. This traditional representation of ED difficulty formulates the price purpose of generating unit as a single quadratic function, this formulation ignores the valve-point effects hence the inaccurate results [5],[7].The realistic ED difficulty is nonlinear, non-smooth, non-convex and more complex owed in occurrence of valve-point loading and ramp limits which complicates the global optimum search [5],[8]. In excess of the precedent decades, a lot of classical techniques have been used for solving the ED problem like linear programming [9], non-linear programming [10], quadratic programming [11], dynamic programming [12], interior point programming [13], mixed integer programming [14], Pattern Search method [15], Lagrangian relaxation algorithm [16] , Newton-Raphson method [17],Lambda 
iteration [18] and Gradient method. These classical methods suffer from some limitations and inconveniences such as: Worse convergence and computational complexity [19], High sensitivity of initial approximate calculations [20], Difficulties in handling nonlinear, non-convex and non-smooth problems [21], The accurate optimum solution is only guaranteed to continuous cost function which does not coincide with the practical ED problem [22], Not applicable to several real- life problems.

The metaheuristics search algorithms have been developed in order to overcome the limits and defaults presented by classical methods [23]. Many metaheuristics algorithms have been used for solving economic dispatch problem as addressed in literature e.g. Differential evolution (DE) [24], genetic algorithm[30], biography algorithm[25], particle swarm optimization algorithm (PSO)[26], artificial bee colony algorithm [27], cuckoo search algorithm[28], bat algorithm[29], bacterial foraging algorithm[36], firefly algorithm[30], flower pollination algorithm[21], chemical reaction optimization[31], grey wolf optimization[32], immune algorithm[33], social spider algorithm[34], teaching learning algorithm[35], gravitational search algorithm[36]. Literature in [45], [37] provides several criteria for classifying metaheuristics algorithms, the highly used among them is the number of candidate solutions handled by every iteration. Based on this criterion [38], [48]: The metaheuristic algorithms are characterized by their natural phenomena imitation and are categorized into two types: single solution based (e.g. Vortex Search Algorithm (VS) [39], Variable Neighborhood Search [40], Simulated Annealing (SA)[41], Tabu Search (TS) [42]) and population-based (e.g. Genetic Algorithm (GA) [43]Cuckoo Search [28],Gravitational Search Algorithm (GSA) [36]). The single solution based algorithm proceeds with only one solution throughout the optimization phase whereas the population based algorithm deals with several solution in the course of optimization. In population-based techniques, the optimal or suboptimal solution coincides to the optimum or is neighborly situated at/or nearly neighbors the optimum.

The population based metaheuristics (P-metaheuristic) algorithms are characterized by their natural phenomena imitation and are categorized in four types [38], [44]: Evolutionary Algorithms (EAs),

Physics-based, Human-based and Swarm Intelligence (SI) algorithms. As I is addressed in [45] EAs imitate characteristics of biological evolution such as recombination, mutation, and selection. Some examples of EA are Genetic Algorithm that is inspired by the Darwinian theory of Evolution, Differential Evolution (DE), Evolutionary Strategy (ES), Evolutionary Programming (EP), and Biogeography-Based Optimization (BBO) algorithm. According to [44], [46] Physics-based algorithms mimic the physical laws. The most popular examples are Gravitational Search Algorithm (GSA), Quantum Mechanics Based Algorithm(QMBA), Electromagnetism Like Algorithm(ELA),Charged System Search(CSS),Central Force Optimization(CFO), Lightning Attachment Procedure Optimization(LAPO). The third category of Pmetaheuristics are inspired by the human behaviors. The most popular examples of human-based algorithms are Imperialist Competitive Algorithm (ICA) [47] Teaching Learning Based Optimization (TLBO) [48], Socio Evolution and Learning Optimization (SELO) [49].The fourth category of P-metaheuristics algorithms consists of algorithms that are inspired by the social conducts of organisms that live in swarms, flocks, or herds, shoals[50].Some examples of this category are Particle Swarm Optimization (PSO), Bat Algorithm (BA), Ant Colony Optimization (ACO),Artificial Bee Colony (ABC),Cuckoo Search Algorithm(CSA), Any metaheuristic algorithms has two main components which are: intensification (exploitation) and diversification (exploration) [38]. Diversification aims at generating different solutions in order to explore the search space to a great extent, whereas intensification concentrates on searching in the local region based on the knowledge ensuring that this region is the location of the current good solution. It is imperative to satisfactorily balance between exploitation and exploration in algorithm so as to avoid the decrease or the increase rate of convergence, and also preventing the algorithm from being caught into local optimum or global optimum [51], [52]. As addressed in [53], the basic single-solution based metaheuristics highly tend to be exploitation oriented while basic populated highly tend to be exploration oriented. In the proposed research, an Improved Chimp Algorithm (ICHIMP) is applied to solve the single area Economic Load Dispatch problem and simulation results show that it outperforms other algorithms addressed in literature.

\section{SINGLE AREA ECONOMIC LOAD DISPATCH PROBLEM FORMULATION}

The foremost purpose of the single area dynamic dispatch is to diminish the entire fuel price of the power generating units subject to the fulfillments of different constraints. 
The overall objective function of the single area dynamic dispatch problem can be categorized to the following subsections:

\subsection{Single Area Dynamic Dispatch-Conventional Approach}

The mathematical formulation of conventional single area dynamic dispatch for one hour can be represented as:

$\left.F\left(P^{G}\right)=\sum_{n=1}^{N G}\left[a_{n}\left(P_{n}^{G}\right)^{2}+b_{n} P_{n}^{G}+c_{n}\right)\right]$

The dispatch of power generating units for ' $\mathrm{H}$ ' Hours may be represented as:

$\left.F\left(P^{G}\right)=\sum_{h=1}^{H}\left(\sum_{n=1}^{N G}\left[a_{n}\left(P_{n}^{G}\right)^{2}+b_{n} P_{n}^{G}+c_{n}\right)\right]\right)$

This eqn.(2) represented the exact mathematical formulation for Dynamic Dispatch. The hour ' $h$ ' may be varied for 1 to $\mathrm{H}$-th Hour for time varying load demand.

All the above mentioned objective functions are subjected to the following equality and inequality constraints:

Power balance constraint

$\sum_{n=1}^{N G} P_{n}^{G}=P^{\text {Demand }}+P^{\text {Loss }}$

Where, the Power Loss, $P^{\text {Loss }}$ may be represented as:

$P^{\text {Loss }}=\sum_{n=1}^{N G} \sum_{m=1}^{N G} P_{n}^{G} B_{n m} P_{m}^{G}$

if $B_{i 0}$ and $B_{00}$ matrices for loss coefficients are given, then the above equation can be modified as:

$P^{L o s s}=P_{n}^{G} B_{n m} P_{m}^{G}+\sum_{n=1}^{N G} P_{n}^{G} \times B_{i 0}+B_{00}$

\section{Generator limit constraint}

The generation of real power of generating units must be within the minimum and maximum operating limits.

$$
P_{n(\min )}^{G} \leq P_{n}^{G} \leq P_{n(\max )}^{G} \quad n=1,2,3, \ldots, N G
$$

\section{Ramp rate limits}

$$
\begin{array}{ll}
P_{n}^{G}-P_{0}^{G_{o}} \leq U R_{n} & n=1,2,3, \ldots, N G \\
P_{n}^{G_{o}}-P_{n}^{G} \leq D R_{n} & n=1,2,3, \ldots, N G
\end{array}
$$

$$
\max \left[P_{n(\max )}^{G},\left(U R_{n}-P_{n}^{G}\right)\right] \leq P_{n}^{G} \leq \min \left[P_{n(\max )}^{G},\left(P_{n}^{G_{o}}-D R_{n}\right)\right]
$$

Prohibited Operating Zones

$$
\left\{\begin{array}{l}
P_{n(\min )} \leq P_{n} \leq P_{n(\min ), 1}^{P O Z} \\
P_{n(\max ), m-1}^{P O Z} \leq P_{n} \leq P_{\min , m}^{P O Z} ; \quad m=2,3, \ldots . N_{P O Z} \\
P_{n(\max ), m}^{P O Z} \leq n_{i} \leq P_{n(\max )} \quad ; m=N_{P O Z}
\end{array}\right.
$$

\section{PROPOSED IMPROVED CHIMP OPTIMIZER}

The advantage of memorization of hunt space clue above the track of iteration compared to other metaheuristics optimization algorithms (MOA) a novel metaheuristic algorithm known as Chimp Optimization Algorithm (chOA) which belongs to Swarm Intelligence Algorithm is proposed. Solitarily the significant swarming behaviors in temperament are the Intelligent Group Haunting (IGH) of chimps. The key sense used for electing the chimps betwixt the various swarming behavior are solitary brilliance and sensual incentive. The procedure of hunting is branched into two aspects: exploration and exploitation. The four major strides of trapping are driving, chasing, blocking and attacking.

The mathematical of independent group, driver, barrier, chaser and attacker are presented.

The prey is sought after during the exploration and exploitation aspects. To mathematically model driving and chasing the prey, eqns. (11) and (12) are proposed.

$$
\left.\vec{D}=\mid \vec{C} \vec{Y}_{\text {Prey }}(\text { iteration })-\xi . \vec{Y}_{\text {Chimp }} \text { (iteration }\right) \mid
$$

$\vec{Y}_{\text {Chimp }}($ iteration +1$)=\vec{Y}_{\text {Prey }}$ (iteration) $-\vec{A} \cdot \vec{D}$

Where $\vec{A}, \xi$, and $\vec{C}$ are the coefficient vectors, t indicates the number of current iteration, $\vec{Y}_{\text {Chimp }}$ is the location vector of a chimp and $\vec{Y}_{\text {Prey }}$ is the vector of prey position. $\vec{A}, \xi$, and $\vec{C}$ vectors are determined by the eqns. (13), (14) and (15), respectively.

$$
\vec{A}=2 \vec{\eta} v_{1}-\vec{\eta}
$$

$\vec{C}=2 v_{2}$

$$
x_{i+1}=1.07 x_{i}\left(7.86 x_{i}-23.31 x_{i}^{2}+28.75 x_{i}^{3}-13.302875 x_{i}^{4}\right)
$$


From 2.5 to 0 non-linearly decrease $\vec{\eta}$ both in exploitation and exploration phase by the iteration process. The range of random vectors of $v_{1}$ and $v_{2}$ are $[0,1]$. Based on various chaotic map, at the last $\xi$ the chaotic vector is calculated such that this vector serves as the cause of sensual incentive of chimps in the trapping process.

Regularly an attacker chimp conducts the hunting process in which driver, barrier and chaser participates. An array to imitate the actions of chimps mathematically, firstly the attacker, driver, barrier and chaser are improved to notify position of the prey. The point of the chimps up till now is to be updated and the message is stored confer to the best chimp positions. This intermediary is suggested by the eqns. (16), (17) and (18)

$$
\begin{aligned}
& \vec{D}_{\text {Attacker }}=a b s\left|\vec{C}_{1} \vec{Y}_{\text {Attack } \mathrm{er}}-\vec{Y}\right| \\
& \vec{D}_{\text {Barrier }}=a b s\left|\vec{C}_{2} \vec{Y}_{\text {Barrier }}-\vec{Y}\right| \\
& \vec{D}_{\text {Chaser }}=a b s\left|\vec{C}_{3} \vec{Y}_{\text {Chaser }}-\vec{Y}\right| \\
& \vec{D}_{\text {Driver }}=a b s\left|\vec{C}_{4} \vec{Y}_{\text {Driver }}-\vec{Y}\right| \\
& \vec{Y}_{1}=\vec{Y}_{\text {Attacker }}-\vec{A}_{1} \cdot \vec{D}_{\text {Attacker }} \\
& \vec{Y}_{2}=\vec{Y}_{\text {Barrier }}-\vec{A}_{2} \cdot \vec{D}_{\text {Barrier }} \\
& \vec{Y}_{3}=\vec{Y}_{\text {Chaser }}-\vec{A}_{3} \cdot \vec{D}_{\text {Chaser }} \\
& \vec{Y}_{4}=\vec{Y}_{\text {Driver }}-\vec{A}_{4} \cdot \vec{D}_{\text {Driver }} \\
& \left.4 \vec{Y}_{1}+\vec{Y}_{2}+\vec{Y}_{4}\right) \\
& \left.\vec{Y}_{1}+1\right)=\frac{\left(\vec{Y}_{1}\right.}{4}+1
\end{aligned}
$$

The initial random position of search agents can be generated using the following mathematical equation:

$$
\vec{Y}_{\text {rand }}=L B_{i}+\xi \times\left(U B_{i}-L B_{i}\right) ; \quad i \in 1,2,3, \ldots, \text { Dim }
$$

\section{TEST SYSTEMS, RESULTS AND DISCUSSION}

Test System-1: The First Test system consist three generators with a load demand of 210 MW. Transmission loss as well as the valve-point effects has been taken into consideration in this test system. The system data are taken from [54]. Using ICHIMP the cost and optimal generations are obtained for Test System and has been shown in Table1. Table-1 shows the lowest cost for the system as $3192.6059 \$ / \mathrm{hr}$.

Table-1. Test Results for Test System-1

\begin{tabular}{|l|l|l|l|l|}
\hline Algorithm & $\begin{array}{l}\text { Standard } \\
\text { deviation }\end{array}$ & $\begin{array}{l}\text { Maximum } \\
\text { fuel } \\
\text { price(\$/hr) }\end{array}$ & $\begin{array}{l}\text { Total Mean } \\
\text { fuel price } \\
\mathbf{( \$ / h r )}\end{array}$ & $\begin{array}{l}\text { Best fuel } \\
\text { price(\$/hr) }\end{array}$ \\
\hline ICHIMP & 0.615607 & 3195.4529 & 3192.98019 & 3192.6059 \\
\hline NSOA[54] & NA & 3206 & NA & 3205.99 \\
\hline GA[54] & NA & 3463.37 & NA & 3252.46 \\
\hline $\begin{array}{l}\text { GA-APO } \\
{[54]}\end{array}$ & NA & 3294.81 & NA & 3341.77 \\
\hline
\end{tabular}

According to the results, ICHIMP performs in obtaining the superlative result for the test system. Since the size is small for this system, it has revealed that a huge numeral of

\begin{tabular}{|c|c|c|c|c|c|c|}
\hline \multirow[b]{2}{*}{$\begin{array}{l}\text { Parameter } \\
\text { s }\end{array}$} & \multicolumn{6}{|c|}{ Algorithms } \\
\hline & $\begin{array}{l}\text { Chim } \\
\text { p }\end{array}$ & $\begin{array}{l}\text { MS } \\
\text { G- } \\
\text { HS[5 } \\
5] \\
\end{array}$ & $\begin{array}{l}\text { PSO } \\
{[55]}\end{array}$ & $\begin{array}{l}\text { NSOA[ } \\
54][55]\end{array}$ & $\begin{array}{l}\text { GA- } \\
\text { APO }[5 \\
4]\end{array}$ & $\begin{array}{r}\text { GA[5 } \\
4][55]\end{array}$ \\
\hline $\begin{array}{l}\text { Maximum } \\
\text { fuel } \\
\text { price(\$/hr) }\end{array}$ & $\begin{array}{l}928.21 \\
17\end{array}$ & $\begin{array}{l}928.5 \\
99\end{array}$ & $\begin{array}{l}928 . \\
43\end{array}$ & $\begin{array}{l}992.481 \\
5\end{array}$ & $\begin{array}{l}1101.4 \\
91\end{array}$ & $\begin{array}{l}1117.1 \\
285\end{array}$ \\
\hline $\begin{array}{l}\text { Best fuel } \\
\text { price( } \$ / h r)\end{array}$ & $\begin{array}{l}925.46 \\
82\end{array}$ & $\begin{array}{l}925.6 \\
41\end{array}$ & $\begin{array}{l}925 . \\
758\end{array}$ & $\begin{array}{l}984.936 \\
5\end{array}$ & $\begin{array}{l}996.03 \\
69\end{array}$ & $\begin{array}{l}996.03 \\
69\end{array}$ \\
\hline $\begin{array}{l}\text { Standard } \\
\text { Deviation }\end{array}$ & $\begin{array}{l}0.6658 \\
08\end{array}$ & NA & NA & NA & NA & NA \\
\hline $\begin{array}{l}\text { Total } \\
\text { Mean fuel } \\
\text { price } \\
\text { (\$/hr) }\end{array}$ & $\begin{array}{l}925.90 \\
43\end{array}$ & $\begin{array}{l}926.8 \\
51\end{array}$ & $\begin{array}{l}925 . \\
76\end{array}$ & NA & NA & NA \\
\hline
\end{tabular}
algorithms converged to the same optimal.

Test System-2: It is comprised of a six generating units supplying a load demand of 283.4 MW and including transmission losses. The information of this system is used from[18],[55][56]. Table-2 illustrates the costs and optimal generations obtained, The best fuel cost and the related transmission loss achieved are $925.4682 \$ / \mathrm{hr}$ and 10.9813MW respectively.

Table-2. Results for Test System-2

Test System-3: In this test system a load demand of $1800 \mathrm{MW}$ is considered with thirteen generating units. Here, the valve-point load effects are considered, whereas 
the transmission line losses are neglected. The data are taken from [56]. Table-3 lists the best fuel price obtained as 17965.2692 \$/hr.

Table-3. Results for SAELD for Test System-3

\begin{tabular}{|l|l|l|l|l|}
\hline Algorithm & $\begin{array}{l}\text { Total } \\
\text { Mean } \\
\text { fuel } \\
\text { price } \\
\mathbf{( \$ / h r )}\end{array}$ & $\begin{array}{l}\text { Maximum } \\
\text { fuel } \\
\text { price(\$/hr) }\end{array}$ & $\begin{array}{l}\text { Best fuel } \\
\text { price(\$/hr) }\end{array}$ & $\begin{array}{l}\text { Standard } \\
\text { deviation }\end{array}$ \\
\hline HMAPSO[57] & 17969.31 & 17969.31 & 17969.31 & NA \\
\hline PSM[58] & 18088.84 & 18233.52 & 17969.17 & NA \\
\hline PSO-SQP[26] & 18029.99 & NA & 17969.93 & NA \\
\hline CGA_MU[59] & NA & NA & 17975.34 & NA \\
\hline QPSO[60] & 18075.11 & NA & 17969.01 & NA \\
\hline EP[26] & 18127.06 & NA & 17994.07 & NA \\
\hline IFEP[56] & 18127.06 & 18267.42 & 17994.07 & NA \\
\hline QPSO[60] & 18075.11 & NA & 17969.01 & NA \\
\hline PSO[89] & 18205.78 & NA & 18030.72 & NA \\
\hline CEP[61] & 18190.32 & 18404.04 & 18048.21 & NA \\
\hline TLBO[62] & NA & NA & 18115 & NA \\
\hline IPSO[63] & 18176.95 & NA & 17998.44 & NA \\
\hline MSL[64] & NA & NA & 18158.68 & NA \\
\hline EP-SQP[26] & 18106.93 & NA & 17991.03 & NA \\
\hline $\begin{array}{l}\text { Imp-Chimp } \\
\text { [Proposed } \\
\text { Algorithm] }\end{array}$ & 17967.69 & 17980.121 & 17965.269 & 3.63518 \\
\hline
\end{tabular}

Test System-4: This test system consist of 20-generators with multiple fuels and valve-point load effects. A load demand of $5400 \mathrm{MW}$ is considered for this system. The information is taken from [2] and the input data of ten units with $2700 \mathrm{MW}$ load demand are duplicated, so that they correspond to 20 units. The transmission losses are neglected in the price function. Table-4 lists the finest fuel price resulted as $1247.8624 \$ / \mathrm{hr}$. It shows that ICHIMP has the lowest cost in comparison with other methods found in [65].

Table-4. Results for 20-unit test system

\begin{tabular}{|l|l|l|l|l|}
\hline Algorithm & $\begin{array}{l}\text { Standard } \\
\text { deviation }\end{array}$ & $\begin{array}{l}\text { Maximum } \\
\text { fuel } \\
\text { price(\$/hr) }\end{array}$ & $\begin{array}{l}\text { Total Mean } \\
\text { fuel price } \\
\mathbf{( \$ / h r )}\end{array}$ & $\begin{array}{l}\text { Best fuel } \\
\text { price(\$/hr) }\end{array}$ \\
\hline IChimp & 0.4596 & 1250.1234 & 1249.085 & 1247.8624 \\
\hline BSA[65] & 0.064 & 1248.2023 & 1248.0459 & 1247.9048 \\
\hline $\begin{array}{l}\text { CGA-MU } \\
{[65]}\end{array}$ & NA & NA & 1249.3893 & NA \\
\hline $\begin{array}{l}\text { IGA-MU } \\
{[65]}\end{array}$ & NA & NA & 1249.1179 & NA \\
\hline
\end{tabular}

Test System-5: This test system consist of 40 generating unit along with valve point effect. A load demand of 10500 MW is considered for this system and the transmission line losses are neglected. The detail system data are adapted from [56]. Table-5 shows the best fuel price obtained as 121415.1246 \$/hr. ICHIMP has the lowest cost in comparison with other methods [43], [56], [26],[66],[67], as seen in Table-5.

Table-5. Results for Test System-5

\begin{tabular}{|c|c|c|c|c|}
\hline Algorithm & $\begin{array}{l}\text { Total Mean } \\
\text { fuel price } \\
(\$ / \mathrm{hr})\end{array}$ & $\begin{array}{l}\text { Maximum } \\
\text { fuel } \\
\text { price(\$/hr) }\end{array}$ & $\begin{array}{l}\text { Standar } \\
\text { d } \\
\text { deviatio } \\
\text { n }\end{array}$ & $\begin{array}{l}\text { Best fuel } \\
\text { price }(\$ / \mathbf{h r})\end{array}$ \\
\hline IChimp & 121420.5 & 121427.3251 & 3.907778 & $\begin{array}{l}121415.124 \\
6\end{array}$ \\
\hline $\mathrm{BSA}[66]$ & 121474.882 & 121524.9577 & NA & 121415.614 \\
\hline HBMO[68] & 122019.65 & $\mathrm{NA}$ & NA & 121416.03 \\
\hline CRO[69] & 121418.03 & 121422.92 & 0.88 & 121416.69 \\
\hline $\mathrm{DE}[43]$ & 121431.47 & 121422.72 & NA & 121416.29 \\
\hline HGA[70] & NA & NA & NA & 121418.27 \\
\hline $\mathrm{DE} / \mathrm{BBO}[71]$ & 121420.89 & 121420.9 & NA & 121420.89 \\
\hline$\theta-\mathrm{PSO}[72]$ & $\begin{array}{l}121509.842 \\
3\end{array}$ & 121852.4249 & 92.3956 & $\begin{array}{l}121420.902 \\
7\end{array}$ \\
\hline $\begin{array}{l}\text { ICA- } \\
\text { PSO[73] }\end{array}$ & NA & NA & NA & 121422.1 \\
\hline CSA[74] & NA & NA & NA & 121425.61 \\
\hline $\mathrm{BBO}[71]$ & $\begin{array}{l}121508.032 \\
5\end{array}$ & 121688.6634 & NA & 121426.953 \\
\hline SA-PSO[73] & NA & NA & $\mathrm{NA}$ & 121430 \\
\hline IA_EDP[33] & $\begin{array}{l}122492.701 \\
8\end{array}$ & 12648.4401 & 182.5274 & $\begin{array}{l}121436.972 \\
9\end{array}$ \\
\hline QPSO[67] & 122225.07 & 121994.0267 & 114.08 & 121448.21 \\
\hline $\mathrm{CSO}[75]$ & $\begin{array}{l}121936.192 \\
6\end{array}$ & $\mathrm{NA}$ & 32 & $\begin{array}{l}121461.670 \\
7\end{array}$ \\
\hline $\begin{array}{l}\text { TSARGA[76 } \\
\text { ] }\end{array}$ & 122928.31 & 124296.54 & 315.18 & 121463.07 \\
\hline $\begin{array}{l}\text { PSO- } \\
\text { RDL[68] }\end{array}$ & NA & $\mathrm{NA}$ & $\mathrm{NA}$ & 121468.82 \\
\hline $\begin{array}{l}\text { SOH- } \\
\text { PSO[71] }\end{array}$ & NA & $\mathrm{NA}$ & NA & 121501.14 \\
\hline CLTBO[77] & 121790.23 & 122116.18 & 150 & 121553.83 \\
\hline $\begin{array}{l}\text { NPSO- } \\
\text { LRS[75] }\end{array}$ & NA & NA & $\mathrm{NA}$ & $\begin{array}{l}121664.430 \\
8\end{array}$ \\
\hline DEC- & 122294.182 & 123722.123 & 14.39 & 121749.189 \\
\hline
\end{tabular}




\begin{tabular}{|l|l|l|l|l|}
\hline SQP[78] & & & & \\
\hline DAA[79] & 121788.7 & NA & NA & 121788.7 \\
\hline $\begin{array}{l}\text { PSO- } \\
\text { SQP[26] }\end{array}$ & 122245.25 & NA & NA & 122094.67 \\
\hline MPSO[80] & NA & NA & NA & 122252.265 \\
\hline EP-SQP[26] & 122379.63 & NA & NA & 122323.97 \\
\hline MSL[64] & NA & NA & NA & 122406.1 \\
\hline TM[81] & 123078.21 & 124693.81 & NA & 122477.78 \\
\hline IFEP[56] & NA & NA & NA & 122624.35 \\
\hline SCA[75] & 125235.128 & 130918.391 & NA & 122713.682 \\
\hline ACO[82] & 121930.58 & 122048.06 & 92.54 & 121811.37 \\
\hline
\end{tabular}

\section{CONCLUSION}

This paper emphasizes the ICHIMP algorithm to Single Area ELD problems in the power systems networks. The improved chimp algorithm has been tested for 3, 6, 13, 20 and 40 -generating units system and it has been experimentally found that the results of the proposed IChimp algorithm are better than other hybrid and recently proposed meta-heuristics search algorithm and such a powerful algorithm may be considered for the solution of Multi-Area Dynamic dispatch problems of electric power system.

economic dispatch problem with valve point effects by incremental artificial bee colony with local search," Appl. Soft Comput. J., vol. 13, no. 5, pp. 2456-2466, 2013.

1. M. Kheshti, X. Kang, Z. Bie, Z. Jiao, and X. Wang, "An effective Lightning Flash Algorithm solution to large scale non-convex economic dispatch with valve-point and multiple fuel options on generation units," Energy, vol. 129, pp. 1-15, 2017.

2. C. L. Chiang, "Improved genetic algorithm for power economic dispatch of units with valve-point effects and multiple fuels," IEEE Trans. Power Syst., vol. 20, no. 4, pp. 1690-1699, 2005.

3. T. Niknam, H. Doagou, and H. Zeinoddini, "Nonsmooth economic dispatch computation by fuzzy and self adaptive particle swarm optimization," Appl. Soft Comput. J., vol. 11, no. 2, pp. 2805-2817, 2011.

4. R. Balamurugan, "Application of shuffled frog leaping algorithm for economic dispatch with multiple fuel options," Proc. - ICETEEEM 2012, Int. Conf. Emerg. Trends Electr. Eng. Energy Manag., pp. 191-197, 2012.

5. K. Zare, M. T. Haque, and E. Davoodi, "Solving non-convex economic dispatch problem with valve point effects using modified group search optimizer method," Electr. Power Syst. Res., vol. 84, no. 1, pp. 83-89, 2012.

6. B. Mohammadi-Ivatloo, A. Rabiee, and A. Soroudi, "Nonconvex dynamic economic power dispatch problems solution using hybrid immune-genetic algorithm," IEEE Syst. J., vol. 7, no. 4, pp. 777-785, 2013.

7. D. C. Walters and G. B. Sheble, "Genetic algorithm solution of economic dispatch with valve point loading," IEEE Trans. Power Syst., vol. 8, no. 3, pp. 1325-1332, 1993.

8. D. Aydin and S. Özyön, "Solution to non-convex
9. A. A. Al-Subhi and H. K. Alfares, "Economic Load Dispatch Using Linear Programming," Int. J. Appl. Ind. Eng., vol. 3, no. 1, pp. 16-36, 2016. Programming Solutions for Load-Flow, MinimumLoss, and Economic Dispatching Problems," IEEE Trans. Power Appar. Syst., vol. PAS-88, no. 4, pp. 399-409, 1969.

11. G. F. Reid and L. Hasdorff, "Economic dispatch using quadratic programming," IEEE Trans. Power Appar. Syst., vol. PAS-92, no. 6, pp. 2015-2023, 1973.

12. Z. X. Liang and J. D. Glover, "A zoom feature for a dynamic programming solution to economic dispatch including transmission losses," IEEE Trans. Power Syst., vol. 7, no. 2, pp. 544-550, 1992.

13. G. Irisarri and a C. a Bagchi, "ispatch with Network and Ramping ints via Interior Point Methods 1," Power, vol. 13, no. 1, pp. 236-242, 1998.

14. M. Azzam, S. E. Selvan, and A. Lef, "Mixed Integer Programming to Globally Minimize the Economic Load Dispatch Problem With Valve-Point Effect11111," no. i, pp. 1-8, 2015.

15. J. S. Alsumait, M. Qasem, J. K. Sykulski, and A. K. Al-Othman, "An improved Pattern Search based algorithm to solve the Dynamic Economic Dispatch problem with valve-point effect," Energy Convers. Manag., vol. 51, no. 10, pp. 2062-2067, 2010.

16. K. S. Hindi and M. R. Ab Ghani, "Dynamic economic dispatch for large scale power systems: a Lagrangian relaxation approach," Int. J. Electr. Power Energy Syst., vol. 13, no. 1, pp. 51-56, 1991.

17. D. Newton-raphson, T. Chen, N. Chen, M. Ieee, and R. Jan, "IEEE Transactions on Energy Conversion,
10. A. M. Sasson and G. J. Fisher, "Nonlinear 
Vol. 10, No. 2, June 1995293 APPLICATION OF THE FAST NEWTON-RAPHSON ECONOMIC DISPATCH AND REACTIVE POWERNOLTAGE DISPATCH," Power, vol. 7, no. 3, pp. 1149-1154, 1992.

18. Z. L. Gaing, "Particle swarm optimization to solving the economic dispatch considering the generator constraints," IEEE Trans. Power Syst., vol. 18, no. 3, pp. 1187-1195, 2003.

19. L. Jebaraj, C. Venkatesan, I. Soubache, and C. C. A. Rajan, "Application of differential evolution algorithm in static and dynamic economic or emission dispatch problem: A review," Renew. Sustain. Energy Rev., vol. 77, no. April, pp. 12061220, 2017.

20. A. Mahor, V. Prasad, and S. Rangnekar, "Economic dispatch using particle swarm optimization: A review," vol. 13, pp. 2134-2141, 2009.

21. A. Y. Abdelaziz, E. S. Ali, and S. M. Abd Elazim, "Implementation of flower pollination algorithm for solving economic load dispatch and combined economic emission dispatch problems in power systems," Energy, vol. 101, pp. 506-518, 2016.

22. M. Mohammadian, A. Lorestani, and M. M. Ardehali, "Optimization of single and multi-areas economic dispatch problems based on evolutionary particle swarm optimization algorithm," Energy, vol. 161, pp. 710-724, 2018.

23. M. Fesanghary and M. M. Ardehali, "A novel metaheuristic optimization methodology for solving various types of economic dispatch problem," Energy, vol. 34, no. 6, pp. 757-766, 2009.

24. N. Noman and H. Iba, "Differential evolution for economic load dispatch problems," Electr. Power Syst. Res., vol. 78, no. 8, pp. 1322-1331, 2008.

25. A. Bhattacharya and P. K. Chattopadhyay, "Expert Systems with Applications Solving complex economic load dispatch problems using biogeography-based optimization," Expert Syst. Appl., vol. 37, no. 5, pp. 3605-3615, 2010.

26. T. A. A. Victoire and A. E. Jeyakumar, "Hybrid PSO-SQP for economic dispatch with valve-point effect," Electr. Power Syst. Res., vol. 71, no. 1, pp. 51-59, Sep. 2004.

27. S. Hemamalini and S. P. Simon, "Dynamic economic dispatch using artificial immune system for units with valve-point effect," Int. J. Electr. Power Energy Syst., vol. 33, no. 4, pp. 868-874, 2011.

28. T. T. Nguyen and D. N. Vo, "The application of one rank cuckoo search algorithm for solving economic load dispatch problems," Appl. Soft Comput. J., vol. 37, pp. 763-773, 2015.

29. A. Kavousi-Fard and A. Khosravi, "An intelligent $\theta$-Modified Bat Algorithm to solve the non-convex economic dispatch problem considering practical constraints," Int. J. Electr. Power Energy Syst., vol. 82, pp. 189-196, 2016.

30. X. Yang, S. Soheil, S. Hosseini, and A. Hossein, "Firefly Algorithm for solving non-convex economic dispatch problems with valve loading effect," Appl. Soft Comput. J., vol. 12, no. 3, pp. 1180-1186, 2012.

31. K. Bhattacharjee, A. Bhattacharya, and S. H. N. Dey, "Chemical reaction optimisation for different economic dispatch problems," IET Gener. Transm. Distrib., vol. 8, no. 3, pp. 530-541, 2014.

32. M. Pradhan, P. K. Roy, and T. Pal, "Oppositional based grey wolf optimization algorithm for economic dispatch problem of power system," Ain Shams Eng. J., vol. 9, no. 4, pp. 2015-2025, 2018.

33. V. S. Aragón, S. C. Esquivel, and C. A. Coello Coello, "An immune algorithm with power redistribution for solving economic dispatch problems," Inf. Sci. (Ny)., vol. 295, pp. 609-632, Feb. 2015.

34. Srinivas Rao J., Srinivasa Varma, P., Suresh Kumar. $\mathrm{T}$, International Journal of Power Electronics and Drive Systems, vol.9, no.3, pp. 1202-1213, 2018.

35. R. Ghanizadeh, S. Majid, and H. Farshi, "Teaching - learning-based optimization for economic load dispatch," 2019 5th Conf. Knowl. Based Eng. Innov., pp. 851-856, 2019.

36. R. K. Swain, N. C. Sahu, and P. K. Hota, "Gravitational Search Algorithm for Optimal Economic Dispatch,” vol. 6, pp. 411-419, 2012.

37. L. Calvet, J. De Armas, D. Masip, and A. A. Juan, "Learnheuristics: Hybridizing metaheuristics with machine learning for optimization with dynamic inputs," Open Math., vol. 15, no. 1, pp. 261-280, 2017.

38. A. A. Heidari, S. Mirjalili, H. Faris, I. Aljarah, M. Mafarja, and H. Chen, "Harris hawks optimization: Algorithm and applications," Futur. Gener. Comput. Syst., vol. 97, pp. 849-872, 2019.

39. B. Dołan and T. Ölmez, "A new metaheuristic for numerical function optimization: Vortex Search algorithm," Inf. Sci. (Ny)., vol. 293, no. August, pp. 125-145, 2015.

40. P. Hansen, N. Mladenović, and J. A. Moreno Pérez, "Variable neighbourhood search: Methods and applications," Ann. Oper. Res., vol. 175, no. 1, pp. 367-407, 2010.

41. S. Kirkpatrick, "Optimization by Simulated Annealing Optimization by Simulated Annealing," vol. 220, no. January 1983, 2014.

42. B. Naama, H. Bouzeboudja, and A. Allali, "Solving the economic dispatch problem by using Tabu Search algorithm," Energy Procedia, vol. 36, pp. 694-701, 2013.

43. T. Yalcinoz, H. Altun, and M. Uzam, "Economic dispatch solution using a genetic algorithm based on 
arithmetic crossover," 2001 IEEE Porto Power Tech Proc., vol. 2, no. 4, pp. 153-156, 2001.

44. A. F. Nematollahi, A. Rahiminejad, and B. Vahidi, "A novel physical based meta-heuristic optimization method known as Lightning Attachment Procedure Optimization," Appl. Soft Comput. J., vol. 59, pp. 596-621, 2017.

45. D. Whitley, "An overview of evolutionary algorithms: Practical issues and common pitfalls," Inf. Softw. Technol., vol. 43, no. 14, pp. 817-831, 2001.

46. A. Biswas, K. K. Mishra, S. Tiwari, and A. K. Misra, "Physics-Inspired Optimization Algorithms: A Survey," J. Optim., vol. 2013, pp. 1-16, 2013.

47. E. Atashpaz-Gargari and C. Lucas, Imperialist competitive algorithm: An algorithm for optimization inspired by imperialistic competition. 2007.

48. R. V. Rao, V. J. Savsani, and D. P. Vakharia, "Teaching-Learning-Based Optimization: An optimization method for continuous non-linear large scale problems," Inf. Sci. (Ny)., vol. 183, no. 1, pp. $1-15,2012$.

49. M. Kumar, A. J. Kulkarni, and S. C. Satapathy, "Socio evolution \& learning optimization algorithm: A socio-inspired optimization methodology," Futur. Gener. Comput. Syst., vol. 81, pp. 252-272, 2018.

50. J. A. Ruiz-vanoye, O. Díaz-parra, F. Cocón, and A. Soto, "Meta-Heuristics Algorithms based on the Grouping of Animals by Social Behavior for the Traveling Salesman Problem," Int. J. Comb. Optim. Probl. Informatics, 2012.

51. J. $\mathrm{Xu}$ and J. Zhang, "Exploration-exploitation tradeoffs in metaheuristics: Survey and analysis," Proc. 33rd Chinese Control Conf. CCC 2014, pp. 8633-8638, 2014.

52. X. S. Yang, S. Deb, and S. Fong, "Metaheuristic algorithms: Optimal balance of intensification and diversification," Appl. Math. Inf. Sci., vol. 8, no. 3, pp. 977-983, 2014.

53. I. Boussaïd, J. Lepagnot, and P. Siarry, "A survey on optimization metaheuristics," Inf. Sci. (Ny)., vol. 237, no. February, pp. 82-117, 2013.

54. T. Nadeem Malik, A. ul Asar, M. F. Wyne, and S. Akhtar, "A new hybrid approach for the solution of nonconvex economic dispatch problem with valvepoint effects," Electr. Power Syst. Res., vol. 80, no. 9, pp. 1128-1136, Sep. 2010.

55. C. Yaşar and S. Özyön, "A new hybrid approach for nonconvex economic dispatch problem with valvepoint effect," Energy, vol. 36, no. 10, pp. 58385845, Oct. 2011.

56. N. Sinha, R. Chakrabarti, and P. K. Chattopadhyay, "Evolutionary programming techniques for economic load dispatch," IEEE Trans. Evol. Comput., vol. 7, no. 1, pp. 83-94, 2003.
57. R. Kumar, D. Sharma, and A. Sadu, "Electrical Power and Energy Systems A hybrid multi-agent based particle swarm optimization algorithm for economic power dispatch," Int. J. Electr. Power Energy Syst., vol. 33, no. 1, pp. 115-123, 2011.

58. J. S. Al-Sumait, J. K. Sykulski, and A. K. AlOthman, "Solution of different types of economic load dispatch problems using a pattern search method," Electr. Power Components Syst., vol. 36, no. 3, pp. 250-265, 2008.

59. Bankupalli, P.T., Srikanth Babu, V., Suresh Kumar. $\mathrm{T}$, "Modelling of static VAR compensator employing a cascaded H-bridged multilevel converter" International Journal of Applied Engineering Research, vol.10, no. 16, pp. 3705737062, 2015

60. K. Meng, H. G. Wang, Z. Y. Dong, and K. P. Wong, "Quantum-inspired particle swarm optimization for valve-point economic load dispatch," IEEE Trans. Power Syst., vol. 25, no. 1, pp. 215-222, 2010.

61. M. S. P. Subathra, S. Easter Selvan, T. Aruldoss Albert Victoire, A. Hepzibah Christinal, and U. Amato, "A hybrid with cross-entropy method and sequential quadratic programming to solve economic load dispatch problem," IEEE Syst. J., vol. 9, no. 3, pp. 1031-1044, 2015.

62. S. Banerjee, D. Maity, and C. K. Chanda, "Teaching learning based optimization for economic load dispatch problem considering valve point loading effect," Int. J. Electr. Power Energy Syst., vol. 73, pp. 456-464, Dec. 2015.

63. M. N. Abdullah, A. H. A. Bakar, N. A. Rahim, J. J. Jamian, and M. M. Aman, "Economic dispatch with valve point effect using iteration particle swarm optimization," Proc. Univ. Power Eng. Conf., no. 1, pp. 1-6, 2012.

64. S. Hemamalini and S. P. Simon, "Maclaurin seriesbased Lagrangian method for economic dispatch with valve-point effect," IET Gener. Transm. Distrib., vol. 3, no. 9, pp. 859-871, 2009.

65. M. Modiri-Delshad, S. H. Aghay Kaboli, E. Taslimi-Renani, and N. A. Rahim, "Backtracking search algorithm for solving economic dispatch problems with valve-point effects and multiple fuel options," Energy, vol. 116, pp. 637-649, Dec. 2016.

66. M. Modiri-Delshad and N. A. Rahim, "Solving nonconvex economic dispatch problem via backtracking search algorithm," Energy, vol. 77, pp. 372-381, Dec. 2014.

67. V. Hosseinnezhad, M. Rafiee, M. Ahmadian, and M. T. Ameli, "Species-based Quantum Particle Swarm Optimization for economic load dispatch," Int. J. Electr. Power Energy Syst., vol. 63, pp. 311322, Dec. 2014.

68. T. Niknam, H. D. Mojarrad, H. Z. Meymand, and B. 
B. Firouzi, "A new honey bee mating optimization algorithm for non-smooth economic dispatch," Energy, vol. 36, no. 2, pp. 896-908, Feb. 2011.

69. P. K. Roy, S. Bhui, and C. Paul, "Solution of economic load dispatch using hybrid chemical reaction optimization approach," Appl. Soft Comput., vol. 24, pp. 109-125, Nov. 2014.

70. D. He, F. Wang, and Z. Mao, "Hybrid genetic algorithm for economic dispatch with valve-point effect," Electr. Power Syst. Res., vol. 78, no. 4, pp. 626-633, Apr. 2008.

71. A. Bhattacharya and P. K. Chattopadhyay, "Hybrid differential evolution with biogeography-based optimization for solution of economic load dispatch," IEEE Trans. Power Syst., vol. 25, no. 4, pp. 1955-1964, 2010.

72. V. Hosseinnezhad and E. Babaei, "Economic load dispatch using $\theta$-PSO,” Int. J. Electr. Power Energy Syst., vol. 49, pp. 160-169, Jul. 2013.

73. J. G. Vlachogiannis and K. Y. Lee, "Closure to discussion on 'economic load dispatch - A comparative study on heuristic optimization techniques with an improved coordinated aggregation-based PSO,"” IEEE Trans. Power Syst., vol. 25, no. 1, pp. 591-592, 2010.

74. M. Basu and A. Chowdhury, "Cuckoo search algorithm for economic dispatch," Energy, vol. 60, pp. 99-108, Oct. 2013.

75. A. I. Selvakumar and K. Thanushkodi, "Optimization using civilized swarm: Solution to economic dispatch with multiple minima," Electr. Power Syst. Res., vol. 79, no. 1, pp. 8-16, Jan. 2009.

76. P. Subbaraj, R. Rengaraj, and S. Salivahanan, "Enhancement of Self-adaptive real-coded genetic algorithm using Taguchi method for Economic dispatch problem," Appl. Soft Comput., vol. 11, no. 1, pp. 83-92, Jan. 2011.

77. X. He, Y. Rao, and J. Huang, "A novel algorithm for economic load dispatch of power systems," Neurocomputing, vol. 171, pp. 1454-1461, Jan. 2016.

78. L. dos Santos Coelho and V. C. Mariani, "Combining of chaotic differential evolution and quadratic programming for economic dispatch optimization with valve-point effect," IEEE Trans. Power Syst., vol. 21, no. 2, pp. 989-996, 2006.

79. G. Binetti, A. Davoudi, D. Naso, B. Turchiano, and F. L. Lewis, "A distributed auction-based algorithm for the nonconvex economic dispatch problem," IEEE Trans. Ind. Informatics, vol. 10, no. 2, pp. 1124-1132, 2014.

80. J. B. Park, K. S. Lee, J. R. Shin, and K. Y. Lee, “A particle swarm optimization for economic dispatch with nonsmooth cost functions," IEEE Trans. Power Syst., vol. 20, no. 1, pp. 34-42, 2005.

81. D. Liu and Y. Cai, "Taguchi method for solving the economic dispatch problem with nonsmooth cost functions," IEEE Trans. Power Syst., vol. 20, no. 4, pp. 2006-2014, 2005.

82. S. Pothiya, I. Ngamroo, and W. Kongprawechnon, "Ant colony optimisation for economic dispatch problem with non-smooth cost functions," Int. J. Electr. Power Energy Syst., vol. 32, no. 5, pp. 478487, 2010. 